\title{
Diagnosis of thymoma metastasis via endobronchial ultrasound-guided transbronchial needle aspiration
}

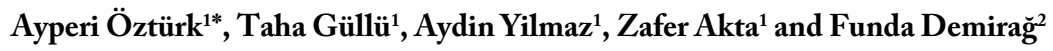 \\ ${ }^{1}$ Interventional Pulmonology Department, Atatürk Chest Diseases and Thoracic Surgery Training and Research Hospital, Turkey \\ ${ }^{2}$ Pathology Department, Atatürk Chest Diseases and Thoracic Surgery Training and Research Hospital, Turkey
}

\section{Introduction}

Thymoma which is arising from epithelial cells of thymus is the most common tumor type in the anterior mediastinal region due to its location. Although seen at any ages it peaked up in 4th and 5th decades with neurological diseases especially myasthenia gravis (MG) [1]. Patients are usually asymptomatic. However neurological diseases were seen in $50 \%$ of symptomatic cases and in $40 \%$ of those a pressure on adjacent tissues as intrathoracic mass was also presented [2]. However a diagnosis of thymoma via fine needle biopsies, such as endobronchial ultrason guided transbronchial needle aspiration (EBUS-TBNA), is difficult to distinguish between various disorders as immunohistochemistry. Moreover, a thymoma is classified in six subtype according to morphology of epithelial cells and the ratio of lymphocytes and epithelial cells. These subtypes are associated with specific clinical features with varying degrees of aggressiveness [3]. Therefore, it is imperative to decide for the subtype of a thymoma before treatment. However, fine needle aspiration can not provide a sufficient specimen for an adequate subclassification [4]. We present a case of thymoma diagnosed by EBUS-TBNA.

\section{Case History}

A 41-year-old male patient was admitted to our hospital for further examination. He had a history of thymectomy that was resulted as thymoma type B2 (minimally invasive type) 9 years after the surgery, a $32 \times 24 \mathrm{~mm}$ mass lesion located lateral to main pulmonary artery and adjacent to superior of left ventricle on control chest computed tomography (CT) was revealed. MG and recurrence thymoma was diagnosed according to accompanying neurological symptoms. $\mathrm{He}$ received azathioprine, corticosteroids, pyridostigmine bromide for 1.5 years. He had also received radiotherapy for pericardial invasion. The mass was being larger during following up and the patient was referred to our clinic for further investigation. On admission to our hospital there was a mass located in anterior mediastinal area in size with $9 \times 9 \times 4$ $\mathrm{cm}$ with a subcarinal lymphadenopathy on chest CT (Figure 1a). We were sampled the subcarinal lymph node by EBUS-TBNA (Figure 1b). The cytological examination of the biopsy showed tumour consisted of ephithelial cells and immature lymphocytes (Figure 2a). The epithelial cells were diffuse positive for keratin 5/6 (Figure 2b). Lymphocytes were immature $\mathrm{T}$ cells and expressing terminal deoxynucleotidyle transferase (TdT), CD1a, CD3 and CD5. The final diagnosis was type B1 Thymoma according to immunehistopathological findings.

\section{Discussion}

EBUS-TBNA is utilised not only for the lymph node staging of lung cancer, but also for diagnosis of other malignant and benign mediastinal diseases [5-7]. Compared to the conventional methods, including CT-guided fine needle aspiration, mediastinoscopy and video-assisted thoracoscopy (VATS), EBUS-TBNA provides a safer and minimal invasive approach for sampling tissues even in the mediastinal region [7]. There is a limited number of thymoma in which diagnosed by EBUS-TBNA [7,8]. Moonim and collegaues diagnosed thymoma by EBUS in 3 of 4 cases of thymic neoplasms [8]. Yoshida and collegaues also report 2 cases of thymomas diagnosed by EBUSTBNA [9]. The most critical disadvantage of EBUS-TBNA is the tiny specimens that may not allow subtyping of thymoma which is crtitical in prognosis and treatment modality. Clinical experience of the cytopathologist is an another problem for thymoma. This is a rare tumor with an incidence of 0,15 per 100.000 and a cytopathologist may not have sufficient experience for an accurate diagnosis [10]. Moonim et al reported succesful diagnosis and subclassification of three cases of thymoma by EBUS-TBNA among 1458 consecutive cases [8]. In two of

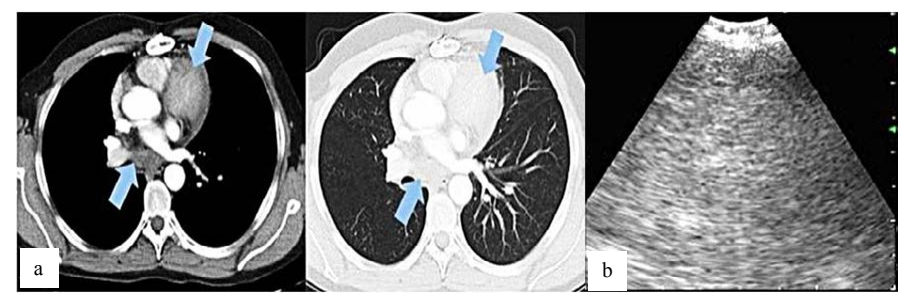

Figure 1: a. Contrast enhanced chest CT showing anterior mediastinal mass and subcarinal lymph node. b. Endobronchial ultrasound showing lymph node with heterogenous hypoechoic echogenicity

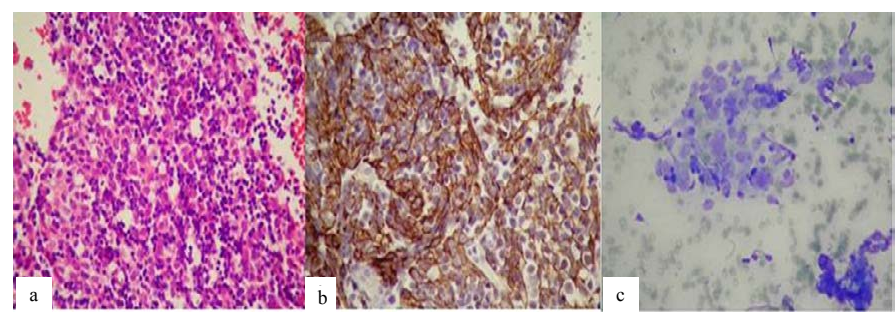

Figure 2: a. The neoplastic epithelial cells within dens nonneoplastic immature lymphocytes (HEX400). b Keratin 5/6 positive epithelial cell network (Keratin 5/6X400). c. Aspirate showing single and clustered tumour cells with lymphocytes (Giemsa X1000).

Correspondence to: Dr. Ayperi ÖZTÜRK, Atatürk Chest Disease and Thoracic Surgery Training and Research Hospital, Department of Pulmonology, Ankara, Turkey, E-mail: drayperi@yahoo.com

Received: December 01, 2016; Accepted: December 29, 2016; Published: December 31, 2016 
them, surgical resection was conducted and histological examination of resected tumor confirmed the results of EBUS-TBNA samples. In our case the immune and histopathological findings showed type $\mathrm{B}_{1}$ thymoma. Tumour consisted of epithelial cells and immature lymphocytes (Figure 2a). The epipthelial cells are diffuse positive keratin 5/6 (Figure 2b). Lymphocytes are immature T cells expressing TdT (terminal deoxynucleotidyle transferase), CD1a, CD3 and CD5. Histopathologic findings showed type $\mathrm{B} 2$ thymoma. Aspirate showing single and clustered epithelial cells with lymphocytes. Epithelial cells show round or elongated nuclei and small nucleoli (Figure2c).

\section{Result}

In summary, here in we reported a case of thymoma diagnosed via EBUS-TBNA by sampling subcarinal lymph node without any complication. EBUS-TBNA is considered to be a less invasive diagnostic technique especially for the tumor of adjacent to trachea and/or main bronchus.

\section{References}

1. Lewis JE, Wick MR, Scheithauer BW, Bernatz PE, Taylor WF (1987) Thymoma. A clinicopathologic review. Cancer 60: 2727-2743. [Crossref]

2. López-Cano M, Ponseti-Bosch JM, Espin-Basany E, Sánchez-García JL, ArmengolCarrasco M (2003) Clinical and pathologic predictors of outcome in thymomaassociated myasthenia gravis. Ann Thorac Surg 76: 1643-1649. [Crossref]
3. Travis WD, Brambilla E, Müller-Hermelink HK, Harris CC (2004) World Health Organization Classification of Tumours, Pathology and Genetics: Tumours of the Lung, Pleura, Thymus and Heart. IARC, Lyon, pp-145-164.

4. Marchevsky A, Marx A, Ströbel P, Suster S, Venuta F, et al. (2011) Policies and reporting guidelines for small biopsy specimens of mediastinal masses. J Thorac Oncol 6: 1724-1729. [Crossref]

5. Senturk A, Babaoglu E, Kilic H, Hezer H, Dogan HT, et al. (2008) Endobronchial ultrasound-guided transbronchial needle aspiration in the diagnosis of lymphoma. Thorax 63: 360-365. [Crossref]

6. Garwood S, Judson MA, Silvestri G, Hoda R, Fraig M, et al. (2007) Endobronchial ultrasound for the diagnosis of pulmonary sarcoidosis. Chest 132: 1298-1304. [Crossref]

7. Yasufuku K, Nakajima T, Fujiwara T, Yoshino I, Keshavjee S (2011) Utility of endobronchial ultrasound-guided transbronchial needle aspiration in the diagnosis of mediastinal masses of unknown etiology. Ann Thorac Surg 91: 831-836. [Crossref]

8. Moonim MT, Breen R, Gill-Barman B, Santis G (2012) Diagnosis and subclassification of thymoma by minimally invasive fine needle aspiration directed by EBUS. Cytopathology 23: 220-228.

9. Yasushi Y, Singyoji M, Ashinuma H, Itakura M, Lizasa T, et al. (2015) Succesful Diagnosis of a thymoma by endobronchial ultrasound-guided transbronchial needle aspiration:A report of two cases. Intern Med 54: 2735-2739. [Crossref]

10. Zakowski MF, Huang J (2010) The role of fine needle aspiration cytology in the diagnosis and management of thymic neoplasia. J Thorac Oncol 5: S281-S285. [Crossref]

Copyright: @2016 ÖZTÜRK A. This is an open-access article distributed under the terms of the Creative Commons Attribution License, which permits unrestricted use, distribution, and reproduction in any medium, provided the original author and source are credited. 